\title{
Time Resolved SEM-SXES Analysis for Lithium Material
}

Yasuaki Yamamoto ${ }^{1}$, Takanori Murano ${ }^{1}$, Hiroshi Onodera ${ }^{1}$, Natasha Erdman ${ }^{2}$, Reiko Matsuda ${ }^{3}$ and Atsunori Matsuda ${ }^{3}$

${ }^{1}$ JEOL Ltd., Akishima, Tokyo, Japan, ${ }^{2}$ JEOL USA Inc., Peabody, Massachusetts, United States, ${ }^{3}$ Toyohashi University of Technology, Toyohashi, Aichi, Japan

Soft X-Ray Spectrometry (SXES) with high energy resolution is a useful method for chemical state analysis of materials by detecting the difference in spectral shape. In recent years, SXES that can be combined with an electron microscope such as Transmission electron microscope (TEM) and Scanning electron microscope (SEM), has been developed [1]. Chemical state analysis of bulk material surfaces can be done well using a low voltage electron beam especially in case of mounting SXES on a Field emissionSEM (FE-SEM). Moreover, it is reported that depth analysis of chemical state and crystalline state is possible by changing the incident voltage [2][3]. However, irradiation of electron beam to a specific location may cause chemical state changes of the beam sensitive specimen such as lithium compound during the observation. Here we report the "time-resolved" SEM-SXES analysis of beam sensitive materials, while optimizing acquisition time of SXES analysis.

We used Schottky FE-SEMs, JEOL JSM-7900F and JSM-F100, combined with the soft X-ray spectrometer, JEOL SS-94000SXES to examine Lithium sulfide (Li2S) powder and charged silicon (Si) negative electrode of a solid lithium ion secondary battery. We utilized a transfer vessel for air isolation to transfer these sample to the SEM-SXES system, to prevent deterioration of the samples due to atmospheric exposure.

SXES point analysis for $\mathrm{Li} 2 \mathrm{~S}$, was obtained at $5 \mathrm{kV}$ and $20 \mathrm{nA}$ probe current (Fig. 1 and Fig. 2). When $\mathrm{Li}_{2} \mathrm{~S}$ is continuously irradiated with an electron beam for several minutes, formation of metallic $\mathrm{Li}$ precipitates on the sample surface can be confirmed in the backscattered electron (BSE) image (as Fig.1). The spectrum of the precipitated Li and S are obtained in the SXES analysis result at an acquisition time of $400 \mathrm{sec}$ (as Fig.2 left). By contrast, in the time-resolved SXES analysis performed every 20 seconds from 0 to 120 seconds, the Li spectrum shape changes in response to the irradiation time (as Fig.2 right). This demonstrates that $\mathrm{Li}$ is metallized as the dose of the electron beam increases.Upper images of Fig. 3 show the result of SXES analysis time-resolved every 60 seconds from 0 to 1200 seconds for charged Si negative electrode of a solid lithium ion secondary battery, obtained at $3 \mathrm{kV}$ accelerating voltage and 20 nA probe current. Comparing the SXES analysis results obtained at $60 \mathrm{sec}$ and $1200 \mathrm{sec}$, peak shift of about $1 \mathrm{eV}$ is seen in the $\mathrm{Li}-\mathrm{K}$ spectrum, and the shape of the $\mathrm{Si}-\mathrm{L}$ spectrum has changed to a shape similar to amorphous $\mathrm{Si}$. Furthermore, we changed the intensity information of this time-resolved spectrum to color level, and tried to image the temporal change (Fig.3 lower). From this figure, it was clarified that the sample was in a stable chemical state up to 300 seconds, and the shift of the Li-K spectrum and the broadening of the $\mathrm{Si}-\mathrm{L}$ spectrum occurred gradually after 300 seconds. As a result, the optimum analysis time for this sample can be determined to be 300 seconds. These results lead to the possibility of a new technique using time-resolved SXES analysis, to determine the optimal analysis time for materials that exhibit chemical state changes due to electron beam irradiation. 

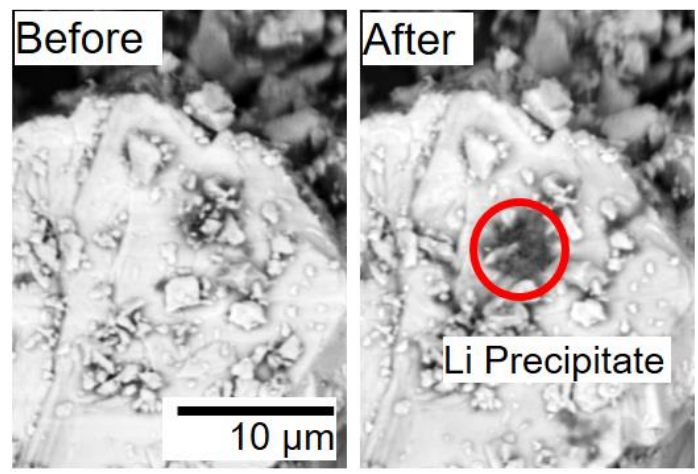

Fig. 1 BSE images of $\mathrm{Li}_{2} \mathrm{~S}$ before and after SXES analysis.
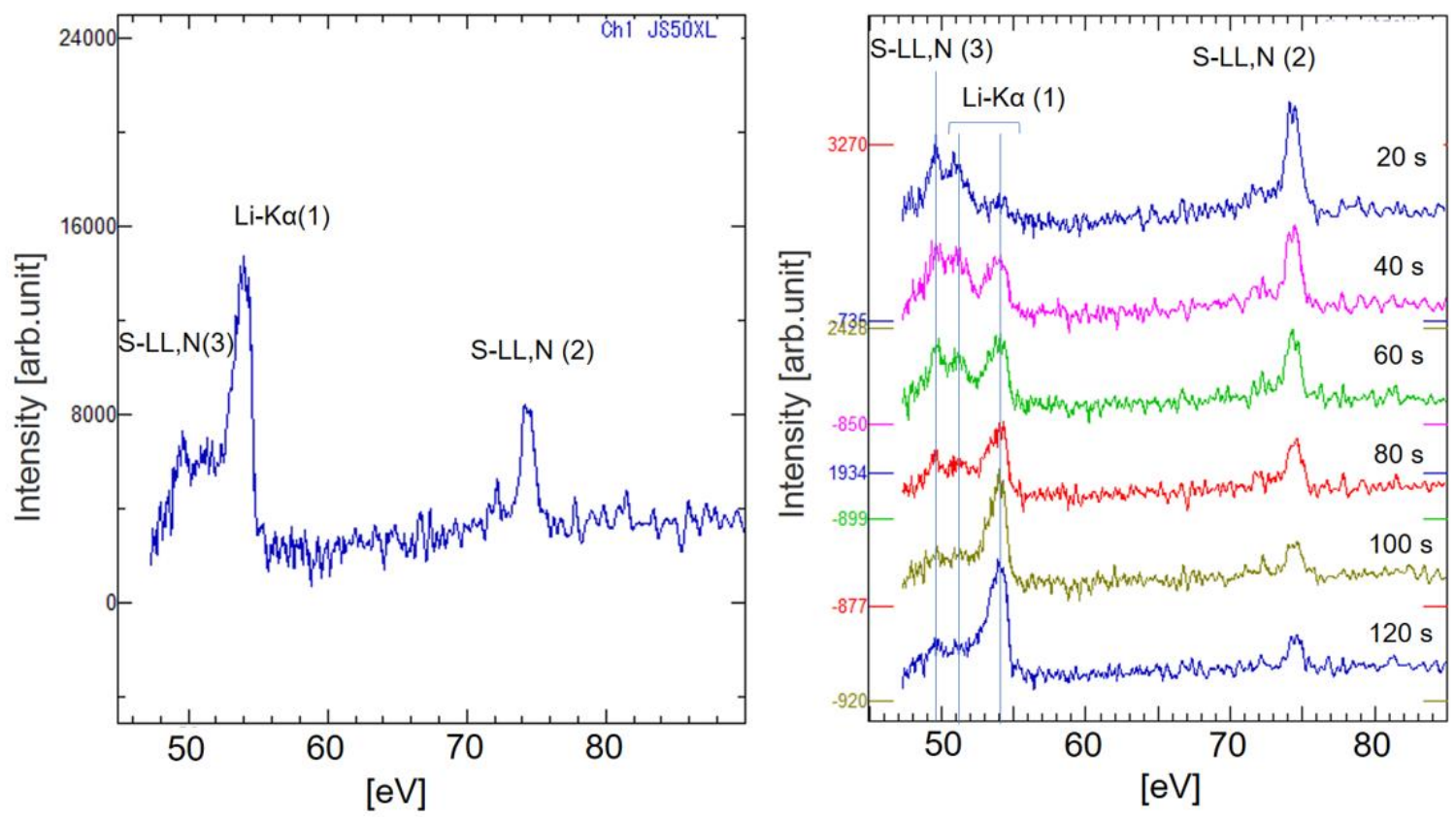

Fig. 2 Spectra of SXES analysis for $\mathrm{Li}_{2} \mathrm{~S}$.

Figure 1. Fig.1 and Fig.2 

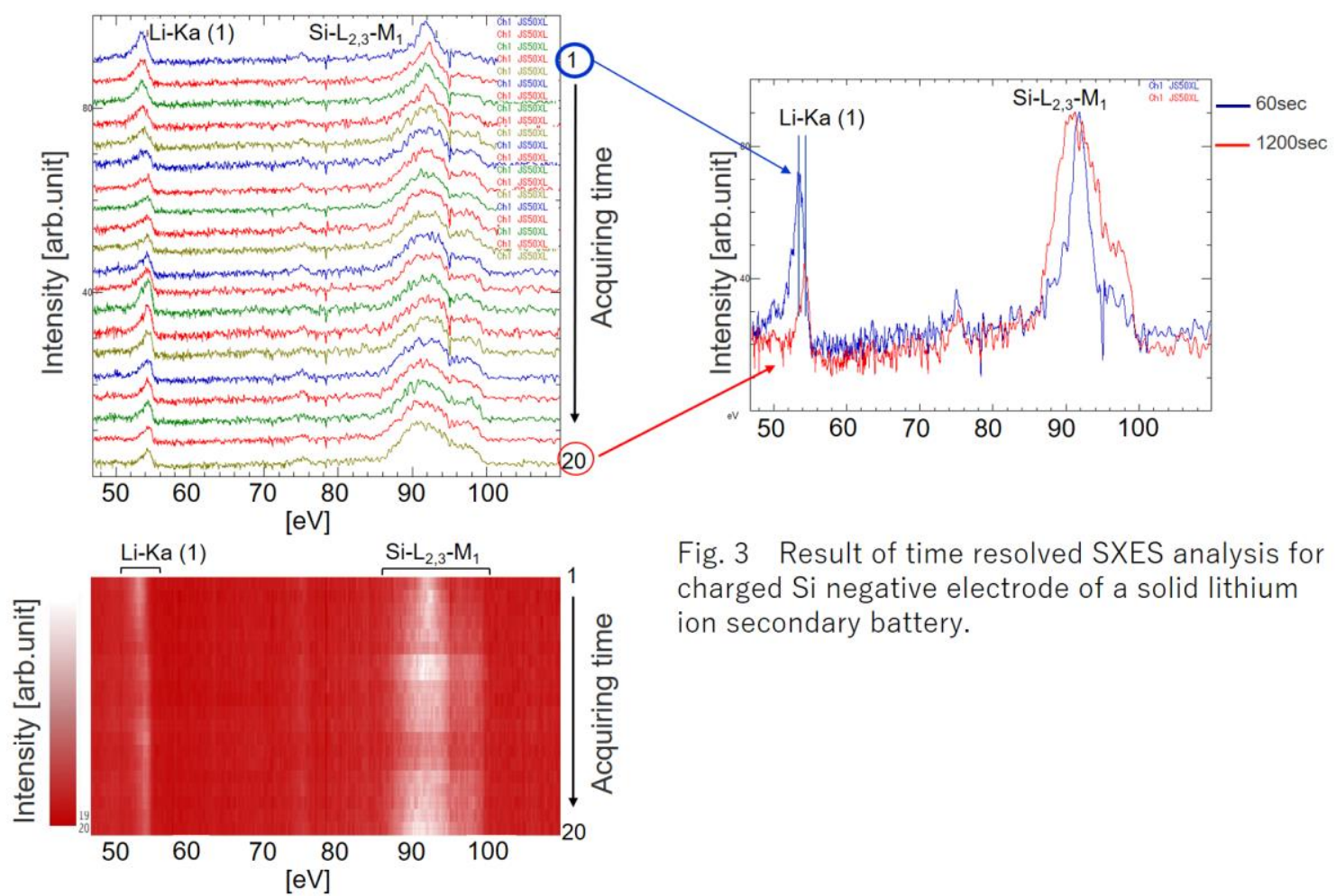

Fig. 3 Result of time resolved SXES analysis for charged Si negative electrode of a solid lithium ion secondary battery.

Figure 2. Fig.3

\section{References}

[1] M. Terauchi et al, Journal of Electron Microscopy, Volume 61, (2012), P. 1-8

[2] H. Takahashi et al, Microscopy and Microanalysis 22(S3):422-423 (2016)

[3] Y. Yamamoto et al, Microscopy and Microanalysis 24(S1):1062-1063(2018) 